\title{
Characterization of Two Orthologs of REVERSION-TO-ETHYLENE SENSITIVITY1 in Apple
}

\author{
Aide Wang ${ }^{1,2} \&$ Kenong $\mathrm{Xu}^{1}$ \\ ${ }^{1}$ Department of Horticulture, Cornell University, New York State Agricultural Experiment Station, Geneva, \\ New York, USA \\ ${ }^{2}$ Present address: Department of Horticulture, Shenyang Agricultural University, Shenyang, Liaoning, China \\ Correspondence: Kenong Xu, Department of Horticulture, Cornell University, New York State Agricultural \\ Experiment Station, Geneva, NY 14456, USA. Tel: 1-315-787-2496. E-mail: kx27@cornell.edu
}

Received: October 15, 2012

Accepted: October 31, 2012

Published: November 20, 2012

doi:10.5539/jmbr.v2n1p24

URL: http://dx.doi.org/10.5539/jmbr.v2n1p24

\begin{abstract}
The Arabidopsis RTE1 (REVERSION-TO-ETHYLENE SENSITIVITY1) and its tomato ortholog GREEN RIPE (GR) are important in plant ethylene signaling, response and/or fruit ripening. To investigate the potential role of RTE1-like genes in apple (M. $\times$ domestica Borkh.) fruit ripening, two orthologs of RTE1 were identified in the apple genome, designated MdRTE1a and MdRTE1b. Using yeast two-hybrid (Y2H) approach, a cDNA prey library was constructed from a pool of maturing/ripening fruit of 'Golden Delicious'. Screening the library with MdRTE1a identified two putative NAC (NAM/ATAF1, 2/UCL2) proteins, designated MdNAC1 and MdNAC2, that interacted with MdRTE1a in yeast cells. MdRTE1b, a closely related paralog of MdRTE1a, was also confirmed to be interactive with MdNAC1 and MdNAC2 using the Y2H system. The expression of MdRTE1 $a$ and MdNACl was high in young fruit but low in more developed and ripening fruit. This pattern of low expression remained largely consistent and was not affected by treatment with 1-methylcyclopropene (1-MCP), an inhibitor of ethylene perception, or ethephon, an ethylene releasing compound. However, the expression of MdRTE1b and MdNAC2 rapidly increased during fruit ripening and was highly inhibited by 1-MCP. These data suggested that MdRTE1a, MdNAC1 and their possible interactions in apple cells may play roles in growth, whereas MdRTE1b, MdNAC2 and their putative interactions are involved in ethylene signaling, response and fruit ripening. The possible interactions between an RTE1-like protein and a NAC protein in plant cells have not been reported thus far. Its implications in ethylene signaling and response are discussed.
\end{abstract}

Keywords: apple, fruit ripening, ethylene, yeast two-hybrid (Y2H), REVERSION-TO-ETHYLENE

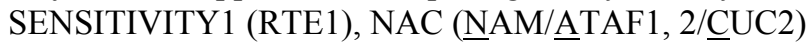

\section{Abbreviations}

ACC: 1-aminocyclopropane-1-carboxylic acid

ACO: ACC oxidase

ACS: ACC synthase

CTR1: CONSTITUTIVE TRIPLE RESPONSE1

EIN2: ETHYLENE INSENSITIVE2

ERF1: ETHYLENE RESPONSE FACTOR1

ETR1: ETHYLENE RESPONSE1

1-MCP: 1-methylcyclopropene

NAC: NAM/ATAF1, 2/CUC2

qRT-PCR: Real-time quantitative reverse transcription polymerase chain reaction

RAN1: RESPONSIVE-TO-ANTAGONIST1

RTE1: REVERSION-TO-ETHYLENE SENSITIVITY1

Y2H: yeast two-hybrid 


\section{Introduction}

The phytohormone ethylene plays critical roles in many biological processes in plants, including plant growth and development, plant response to biotic and abiotic stresses, and ripening of climacteric fruit such as tomato and apple. Biosynthesis of ethylene has been well defined in the Yang cycle that mainly involves two enzymes: 1-aminocyclopropane-1-carboxylic acid (ACC) synthase (ACS) and ACC oxidase (ACO) (Adams \& Yang, 1979; Yang \& Hoffman, 1984). There are two systems of ethylene production in plants: System 1 occurs during plant/fruit growth and development, and System 2 is exclusively in floral senescence and fruit ripening (Barry \& Giovannoni, 2007). There are at least five ACS (MdACS1-5) and four ACO (MdACO1-4) genes in apple (Kondo, Meemak, Ban, Moriguchi, \& Harada, 2009; Wiersma, Zhang, Lu, Quail, \& Toivonen, 2007) and these genes appear to operate similarly in the two systems for ethylene production. MdACS1 and MdACO1 are considered System 2 genes as their expression is highly correlated with the ethylene production burst in ripening apple fruit.

Much insight into the ethylene signal transduction and response has been gained from studies in Arabidopsis. The linear cascade of ethylene signal transduction, which includes ETR1 (ETHYLENE RESPONSE1) and other ethylene receptors, RAN1 (RESPONSIVE-TO-ANTAGONIST1), CTR1 (CONSTITUTIVE TRIPLE RESPONSE1), EIN2 (ETHYLENE INSENSITIVE2), EIN3 and EILs (EIN3 Like) and ERF1 (ETHYLENE RESPONSE FACTOR1), has become more complex as recent evidence suggests that regulators in other pathways, as well as mechanisms of feedback and elements of protein turnover machinery are involved in ethylene signal transduction and response (Kendrick \& Chang, 2008; Stepanova \& Alonso, 2009). An important finding is the discovery of REVERSION-TO-ETHYLENE SENSITIVITY1 (RTE1), which is a membrane protein highly conserved in plants and specifically interacts with ETR1 to regulate ethylene signaling in Arabidopsis (Dong et al., 2010; Resnick, Rivarola, \& Chang, 2008; Resnick, Wen, Shockey, \& Chang, 2006; Rivarola, McClellan, Resnick, \& Chang, 2009; Zhou, Liu, Xie, \& Wen, 2007). Moreover, GREEN RIPE (GR), an ortholog of RTE1, is directly involved in both ethylene signaling and fruit ripening in tomato in a primarily fruit tissue specific manner (Barry \& Giovannoni, 2006; Barry et al., 2005).

In apple fruit, major elements in the linear model of ethylene signaling have been identified. There are six apple ethylene receptor genes: MdETR1, MdETR1b, MdETR2, MdETR5, MdERS1 and MdERS2. Studies of these ethylene receptors have focused on understanding their roles in apple shelf life by quantifying the levels of their mRNA and/or protein accumulation (Tatsuki \& Endo, 2006; Tatsuki, Endo, \& Ohkawa, 2007; Tatsuki, Hayama, \& Nakamura, 2009; Wang et al., 2009; Wiersma et al., 2007). The transcript levels of MdETR1 and MdERS1 were also evaluated in a study of ethylene biosynthesis and perception in apple fruitlet abscission (Dal Cin, Danesin, Boschetti, Dorigoni, \& Ramina, 2005).

Several members of the negative regulator CTR1 are likely encoded by the apple genome, as multiple CTR1-like genes exist in tomato (Adams-Phillips et al., 2004; Lin, Alexander, Hackett, \& Grierson, 2008; Zegzouti et al., 1999). To date, only MdCTR1 has been described in apple. The conserved 3' end of the MdCTR1 coding region (AY670703) was cloned by Dal Cin et al. (2005). Its full length cDNA was characterized by several alternative splicing variants (DQ847147-DQ847149) (Wiersma et al., 2007). Expression of MdCTRldoes not change widely in ripening fruit of several apple cultivars studied, including 'Golden Delicious' (Dal Cin et al., 2007; Dal Cin, Rizzini, Botton, \& Tonutti, 2006; Wiersma et al., 2007), 'Sunrise' (Wiersma et al., 2007) and 'Delicious' (Li \& Yuan, 2008).

Efforts dedicated to MdEIN2 have been limited and its full-length cDNA clone is not available. In contrast to the uniqueness of the EIN2 gene in Arabidopsis, two MdEIN2 genes, MdEIN2A (CV084546) and MdEIN2B (CO066480) were designated to distinguish the two distinct pools of apple EST (expressed sequence tag) sequences in GenBank that are all similar to the C-terminus of EIN2 (Wiersma et al., 2007). As expected, the transcript levels of MdEIN2A and MdEIN2B undergo little variation in fruit, either pre- or post- harvest (Wiersma et al., 2007).

The three EIN3-like genes, MdEIL1 (GU732484), MdEIL2 (GU732485) and MdEIL3 (GU732486), were studied in apple (Tacken et al., 2010). Expression of MdEIL1 and MdEIL3 remained at a constant level during fruit ('Royal Gala') development. However, mRNA levels of MdEIL2 increased progressively along with the fruit development and peaked at harvest with a relative expression ratio greater than 10-fold, suggesting that MdEIL2 may contribute more to ethylene sensitivity during fruit ripening than other EIN3-like genes (Tacken et al., 2010).

MdERF1 and MdERF2 are the first two primary target transcription factors isolated and characterized in apple. Expression of the two MdERFs is not only specific to ripening fruit (predominantly for $M d E R F 1$, exclusively for $M d E R F 2$ ), but also positively regulated by ethylene, strongly suggesting that they are involved in fruit ripening 
(Wang, Tan, Takahashi, Li, \& Harada, 2007). A screening of 38 putative MdERF genes for their expression patterns during 'Royal Gala' fruit development and in response to exogenous ethylene treatment identified 17 of these genes were predominately expressed at $35 \mathrm{DAF}$ (days after full-bloom), two primarily expressed at 132 DAF, and two (AP2D29 and AP2D19) were most sensitive to $4 \mathrm{~h}$ ethylene treatment (Tacken et al., 2010).

However, studies of the apple orthologs of RTE1 or GR have not been documented. To investigate their potential role in apple fruit ripening and firmness retention, two apple orthologs, designated MdRTE1a and MdRTE1b, of RTE1 were identified in the draft sequence of the apple genome (Velasco et al., 2010) and MdRTE1a was used to screen a cDNA prey library constructed from 'Golden Delicious' (GD) based on yeast two-hybrid (Y2H) system in this study. Instead of identifying the expected ETR1-like ethylene receptors, two putative members of the large gene family of NAC (NAM/ATAF1, 2/UC2) transcription factors, designated MdNAC1 and MdNAC2, were found to interact with MdRTE1a and MdRTE1b in the yeast cells. qRT-PCR analyses demonstrated that the expression of MdRTE1b and MdNAC2 was highly regulated by ethylene while that of MdRTE1a and MdNAC1 remained largely consistent at low levels in maturing/ripening fruit, and therefore unresponsive to ethylene signaling.

\section{Materials and Methods}

\subsection{Y2H Library Construction}

Fruit of 'Golden Delicious' (GD), the genome of which has been sequenced (Velasco et al., 2010), were chosen for the Y2H library construction. The fruit were collected from the experimental orchards in Geneva, New York at three time points: $\mathrm{d}-19$ (18 September 2009, 5 fruit), d 0 (8 October 2009, commercial harvest, 5 fruit) and d 6 (14 October 2009, 25 fruit). The 25 fruit harvested at d 6 were kept at room temperature $\left(24^{\circ} \mathrm{C}\right)$ for a series of five samplings ( 5 fruit per sample) at d 6, d 11, d 16, d 21 and d 26. For each sample, the five fruit were cut into slices, frozen in liquid nitrogen and stored at $-80{ }^{\circ} \mathrm{C}$ prior to RNA isolation.

Total RNA was isolated from each of the seven GD fruit samples (d -19, d 0, d 6, d 11, d 16 and d 21 and d 26) as described previously (Lay-Yee, Dellapenna, \& Ross, 1990). For the Y2H library construction, mRNA was isolated from the total RNA of $980 \mu \mathrm{g}$ that were evenly pooled from the seven samples (140 $\mu \mathrm{g}$ per sample) using the Ambion (Austin, Texas, USA) Poly(A) Purist Kit. The library was constructed with Make Your Own Mate \& Plate Library System (Clontech, Mountain View, CA, USA) following the manufacturer's instructions. Briefly, the first-strand cDNA was synthized from $1 \mu \mathrm{g}$ mRNA with the Oligo-dT primers (CDSIII Primer, Table 1). The cDNA was amplified by Long Distance PCR (LD-PCR) with 5' PCR primer and 3' PCR primer (Table 1) for 20 cycles to generate double-strand cDNA, which was then purified by the CHROMA SPIN TE-400 column. After purification, the double-strand cDNA of $3.4 \mu \mathrm{g}$ was ligated into SmaI-linearized pGADT7-Rec cloning vector (Clontech) and subsequently transformed into yeast strain Y187 to generate the cDNA library for Y2H assay using Yeastmaker Yeast Transformation System 2 (Clontech) according to the manufacturer's instruction.

\subsection{Construction of the Bait Constructs and Transformation of Yeast Cell}

To identify the apple orthologs of RTE1, its protein sequence (NP_180177.2) was blast searched against the Malus EST databases in GenBank using the TBLASTN program. An apple UniGene Mdo.6837 (UGID: 1406185), consisting of 16 Malus ESTs (expressed sequence tags), was found that was similar to RTE1 (71.1\% identity over all 242 amino acids of RTE1). Inspecting the 16 ESTs indicated that they represent two closely related genes: One group of seven ESTs is for MDP0000225233 (apple gene/protein ID at GDR (Genome Database for Rosaceae), http://www.rosaceae.org/), a predicted gene on chromosome 15, designated MdRTE1a; the other group of 9 ESTs for gene MDP0000341171 on chromosome 8, designated MdRTE1b. MdRTE1a and MdRTE1b share $94.1 \%$ identity in deduced amino acid sequences (Figure 1A).

The full length coding sequence of MdRTEla was PCR amplified with primers KT7_RTE1F (attached with an EcoRI site at 5' end) and KT7_RTE1R (attached with a BamHI site at 5' end) (Table 1) from the cDNA of the GD fruit to create the MdRTE1a bait construct. The PCR products were restricted with EcoRI and BamHI, and cloned into pGBKT7 vector (Clontech) that was already linearized with the same two enzymes. MdRTE1b was similarly amplified and cloned, but with primers KT7_RTE1F2 and KT7_RTE1R (Table 1). The primer bases discriminating MdRTE1a from MdRTE1b were found in KT7_RTE1F and KT7_RTE1F2 (Table 1). The resulting recombinant plasmids pGBKT7-RTE1a and pGBKT7-RTE1b were confirmed by sequencing with T7 primer (Table 1) and then transformed into yeast strain Y2HGold using Yeastmaker Yeast Transformation System 2 (Clontech) with minor modifications. Briefly, $5 \mathrm{ml} \mathrm{1 \times}$ YPDA liquid medium was inoculated with a fresh yeast (Y2HGold) colony and incubated at $30^{\circ} \mathrm{C}$ with shaking at $250 \mathrm{rpm}$ for no more than $14 \mathrm{~h}$. The cells were collected by centrifugation at $700 \times \mathrm{g}$ for $5 \mathrm{~min}$, and then washed once with $5 \mathrm{ml}$ sterile water and once with 
$750 \mu 11.1 \times \mathrm{TE} / \mathrm{LiAc}$ (lithium acetate) solution $\left(1.1 \mathrm{ml}\right.$ of $10 \times \mathrm{TE}$ and $1.1 \mathrm{ml}$ of $10 \times \mathrm{LiAc}(1 \mathrm{M})$ in $\left.10 \mathrm{ml} \mathrm{H}_{2} \mathrm{O}\right)$. The washed cells were collected by centrifuging at $700 \times \mathrm{g}$ for $5 \mathrm{~min}$, and then resuspended in $50-100 \mu 11.1 \times$ $\mathrm{TE} / \mathrm{LiAc}$ solution for transformation. A mix of $50 \mu \mathrm{l}$ of cells, $100 \mathrm{ng}$ of construct DNA, $5 \mu \mathrm{l}$ of Yeastmaker Carrier DNA at $10 \mu \mathrm{g} / \mu \mathrm{l}$, and $500 \mu \mathrm{l}$ of PEG/LiAc (containing 40\% PEG 3350, $1 \times$ TE and $1 \times \mathrm{LiAc}$ ) was made and incubated at $30^{\circ} \mathrm{C}$ for 2-3 h with gentle shaking, and then $20 \mu \mathrm{l}$ DMSO (dimethyl sulfoxide) was added to the mixture and incubated at $42^{\circ} \mathrm{C}$ for $15 \mathrm{~min}$. The cells were gently mixed every 5 min during the incubation, and later were collected by centrifugation at $16,000 \times \mathrm{g}$ for $15 \mathrm{~s}$. The pellets were resuspended in $500 \mu 11 \times$ YPDA and incubated at $30^{\circ} \mathrm{C}$ for $60-90 \mathrm{~min}$ with shaking at $160 \mathrm{rpm}$. The cells were harvested again by centrifuging at $16,000 \times \mathrm{g}$ for $15 \mathrm{~s}$ and finally resuspended in $0.9 \%$ of $\mathrm{NaCl}$ solution $(200-400 \mu \mathrm{l})$ and plated on the single dropout (SD/-Trp) plates for evaluation of transformation efficiency and positive bait colonies.

Table 1. List of primer names and their sequences

\begin{tabular}{ll}
\hline Primer name & Sequence (5'-3') \\
\hline CDS III & ATTCTAGAGGCCGAGGCGGCCGACATG-d(T) ${ }_{30} V^{*}{ }^{*}$ \\
5' PCR primer & TTCCACCCAAGCAGTGGTATCAACGCAGAGTGG \\
3' PCR primer & GTATCGATGCCCACCCTCTAGAGGCCGAGGCGGCCGACA \\
KT7_RTE1F ${ }^{\mathrm{a}}$ & GCCGAATTCATGATGGAGCTAAAGGAAGCTTATG \\
KT7_RTE1F2 ${ }^{\mathrm{a}}$ & GCCGAATTCATGATGGAGCTGAAAGAAGCGTATG \\
KT7_RTE1R ${ }^{\mathrm{b}}$ & GCCGGATCCCTAGCAGCAAGGTCTTG \\
T7 & TAATACGACTCACTATAGGG \\
ex_RTE1aF & GAAGCTTATGACATCGAGCGTA \\
ex_RTE1aR & GCTACGGAACCAAATGTGAAA \\
ex_RTE1bF & GAAGCGTATGACATTGAGCATT \\
ex_RTE1bR & ACGGCACCAAATGCAAAG \\
ex_NAC1F & TTCAGCTGTCGCAGAATGAT \\
ex_NAC1R & GCATCTTCCCCTAGTCAGCAG \\
ex_NAC2F & TGTTCAGCTGTCACAGGATGAC \\
ex_NAC2R & CATGCTTCTTCCCCTAATCACTAA \\
Actin F & GGCTGGATTTGCTGGTGATG \\
Actin R & TGCTCACTATGCCGTGCTCA \\
Y2H_amp F & CTATTCGATGATGAAGATACCCCACCAAACCC \\
Y2H_amp R & GTGAACTTGCGGGGTTTTTCAGTATCTACGATT \\
\hline
\end{tabular}

${ }^{\mathrm{a}}$ The primer bases discriminating MdRTE1a from MdRTE1b are highlighted in gray;

${ }^{\mathrm{a}, \mathrm{b}}$ The bases underlined show the restriction site of EcoRI and BamHI, respectively;

$* \mathrm{~N}=\mathrm{A}, \mathrm{T}, \mathrm{G}$ or $\mathrm{C} ; \mathrm{V}=\mathrm{A}, \mathrm{G}$ or $\mathrm{C}$.

\subsection{Y2H Library Screening}

The bait clone of construct pGBKT7-RTE1a was used to initially screen the Y2H library with the GAL4-based Matchmaker Gold Yeast Two-Hybrid System (Clontech) according to the manufacturer's instructions. Briefly, 4 $\mathrm{ml}$ of the bait strain overnight cultures (SD/-Trp liquid medium), $1 \mathrm{ml}$ of library aliquot $\left(1.2 \times 10^{7}\right.$ cells $)$ and 45 $\mathrm{ml} 2 \times$ YPDA medium were combined in a 21 flask and incubated at $30^{\circ} \mathrm{C}$ for $20 \mathrm{~h}$ with shaking at $50 \mathrm{rpm}$, and then checked for the formation of zygotes under a Zeiss (Oberkochen, Germany) Axioskop phase contrast microscope (40×). When zygotes were present, the cells were collected by centrifugation at 1,000 $\times \mathrm{g}$ for $10 \mathrm{~min}$, and resuspended in $10 \mathrm{ml}$ of $0.5 \times$ YPDA medium. The mated cell cultures were spread on the SD/-Trp/-Leu/X/A or $\mathrm{DDO} / \mathrm{X} / \mathrm{A}$ plates (containing double dropout $\mathrm{SD}$ medium that lacks tryptophan and leucine, but is supplemented with $\mathrm{X}-\alpha-\mathrm{Gal}$, the substrate of $\alpha$-galactosidase encoded by the reporter gene MEL1, and Aureobasidin A, a new yeast antibiotic that kills all cells of non-hybrids and acts as a selection marker in the Matchmaker Gold Yeast Two-Hybrid System) and kept at $30^{\circ} \mathrm{C}$. Positive colonies appeared within $5 \mathrm{~d}$ and were streaked onto plates of quadruple dropout SD medium lacking tryptophan, leucine, histidine and adenine while 
containing X- $\alpha-\mathrm{Gal}$ and Aureobasidin A, i.e. the SD/-Trp/-Leu/-His/-Ade/X/A, or QDO/X/A plates, for high stringency screening. Genuine positive hybrid colonies appeared in $5 \mathrm{~d}$ on these QDO/X/A plates. The plasmids were rescued from the colonies survived on QDO/X/A plates using Easy Yeast Plasmid Isolation Kit (Clontech), which were then transformed into E. coli strain JM109 and plated on LB plate with $100 \mathrm{mg} / \mathrm{ml}$ ampicillin to select the prey plasmids. To reveal the identity of the prey plasmids, their inserts were sequenced with $\mathrm{T} 7$ primer (Table 1).

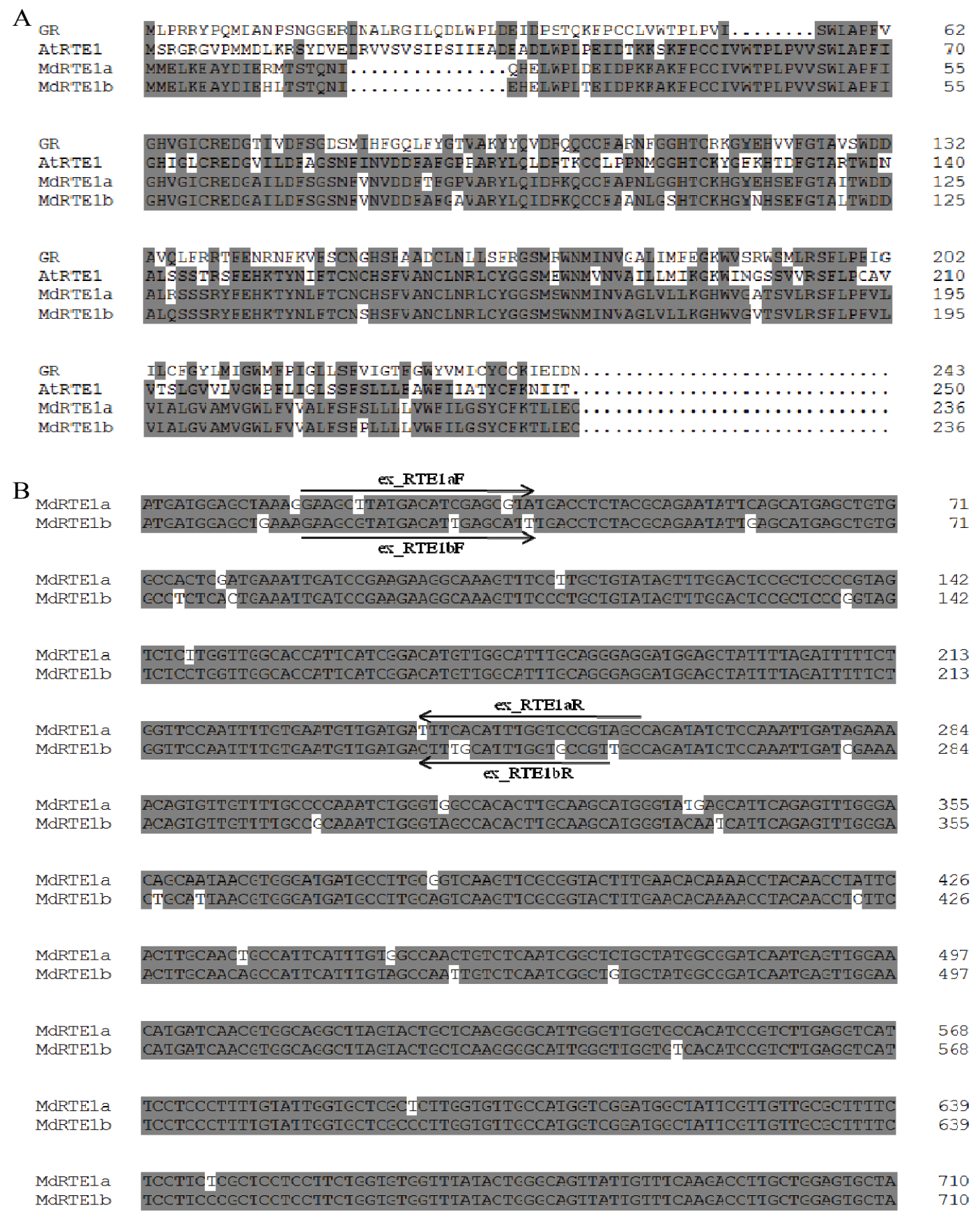

Figure 1. Sequence information of MdRTE1a and MdRTE1b

A: Alignment of predicted amino acid sequences of GR, RTE1, MdRTE1a, and MdRTE1b. The accession numbers of the aligned sequences are ABD34613.1 (GR, tomato), NP_180177.2 (AtRTE1, Arabidopsis), MDP0000225233(MdRTE1a, apple), and MDP0000341171 (MdRTE1b, apple). Amino acid residues that are conserved (present in more than three of the four accessions) were highlighted in gray. B: Alignment of coding region of MdRTE1a and MdRTE1b. The last base "G" in the stop codon was not shown at the end of the sequences. The primers used for gene expression assays were indicated with arrows. 
Table 2. Date (2010) and number of 'Golden Delicious' fruit harvested for qRT-PCR assay and/or evaluation of fruit ethylene production and firmness

\begin{tabular}{|c|c|c|c|c|c|c|c|c|c|c|c|c|c|c|c|c|c|c|c|}
\hline \multirow[t]{2}{*}{ Variety } & Date/ & \multicolumn{18}{|c|}{ Number of fruit sampled } \\
\hline & $\begin{array}{l}\text { Days after } \\
\text { Harvest }\end{array}$ & & & & & & & & & & & & & & & & & & \\
\hline \multirow[t]{5}{*}{ GD } & DAF & 7 & 15 & 22 & 28 & 35 & 42 & 56 & 70 & 84 & 98 & 112 & 126 & 133 & 140 & & & & \\
\hline & Date & $5 / 11$ & $5 / 19$ & $5 / 26$ & $6 / 1$ & $6 / 8$ & $6 / 15$ & $6 / 29$ & $7 / 13$ & $7 / 27$ & $8 / 10$ & $8 / 24$ & $9 / 7$ & $9 / 14$ & $9 / 21$ & $10 / 3$ & $10 / 8$ & $10 / 13$ & $10 / 18$ \\
\hline & Normal & $>10$ & $>10$ & $>10$ & 5 & 5 & 5 & 5 & 5 & 5 & 5 & 5 & 5 & 5 & $25 / 5^{\mathrm{a}}$ & 5 & 5 & 5 & 5 \\
\hline & 1-MCP & & & & & & & & & & & & & & $20 / 0^{\mathrm{b}}$ & 5 & 5 & 5 & 5 \\
\hline & Ethephon & & & & & & & & & & & & & & $20 / 0^{b}$ & 5 & 5 & 5 & 5 \\
\hline \multirow[t]{2}{*}{ Fuji } & Date & & & & & & & & & & & & & & $10 / 13$ & $10 / 18$ & $10 / 23$ & $10 / 28$ & $11 / 4$ \\
\hline & Normal & & & & & & & & & & & & & & $25 / 5^{\mathrm{a}}$ & 5 & 5 & 5 & 5 \\
\hline
\end{tabular}

${ }^{a}$ The 25 fruit were divided into five groups of five. One group was sampled immediately at harvest as control and each of the rest groups were sampled every five days as shown.

${ }^{b}$ The 20 fruit were treated and no fruit were sampled after immediate treatment. These fruit were divided into four groups of five and then sampled one group every five days as shown.

\subsection{Co-transformation of Yeast Cells}

To further confirm the interaction, plasmids of $100 \mathrm{ng}$ of bait and $100 \mathrm{ng}$ of positive prey clones were co-transformed into the Y2HGold yeast strain using Yeastmaker Yeast Transformation System 2 (Clontech) with minor modification as described in section 2.2 Construction of the bait constructs and transformation of yeast cell. The co-transformed cells were placed on the DDO/X and DDO/X/A plates.

\subsection{Fruit Sampling and Treatment for Gene Expression Assay and/or Evaluation of Fruit Ethylene Production and Firmness}

The fruit of GD were sampled over the entire growth, development and maturing stages in 2010. Starting from 7 days after full-bloom (7 DAF, 11 May 2010) through commercial harvest (140 DAF, 21 September 2010), a total of 14 samples were collected (Table 2). For the 7 to 22 DAF samples, the whole fruit were pooled with the petiole removed, and at least ten fruit were used for each sampling date. For the rest of the samples, only the cortex tissues were used and at least five fruit were pooled for each sample.

At commercial harvest, in addition to the five fruit sampled regularly, another 60 fruit of GD were harvested and divided into three batches of 20 fruit each for the following treatments, which were all conducted under room temperature $\left(24^{\circ} \mathrm{C}\right)$. The first 20 fruit were treated with $1 \mu \mathrm{l}^{-1}$ 1-MCP (Agrofresh, Philadelphia, PA, USA) for $24 \mathrm{~h}$ at the Cornell Postharvest Research Facility, and then placed in a regular room. The second 20 fruit, at the same time, were dipped into $500 \mathrm{mg} / 1$ ethephon solution (Sigma-Aldrich, St. Louis, MO, USA) for $10 \mathrm{~s}$ and then sealed in a container holding for $24 \mathrm{~h}$ at room temperature. The third batch was the untreated control. Fruit sampling was similar in these three treatments: one group of five fruit was sampled at 5,10,15 and $20 \mathrm{~d}$ after commercial harvest (Table 2).

In addition, 25 fruit of 'Fuji' were also sampled at commercial harvest (13 October 2010). Without being treated, the 'Fuji' fruit were sampled in the same manner as the untreated GD fruit, and used as a low ethylene production cultivar control (Table 2). The flowers and leaves of GD were sampled at 7 DAF (11 May 2010). All samples were immediately frozen in liquid nitrogen and stored at $-80{ }^{\circ} \mathrm{C}$ for RNA isolation, except for the fruit harvested at commercial harvest that need to be treated and stored as described above and to be evaluated as follows. 


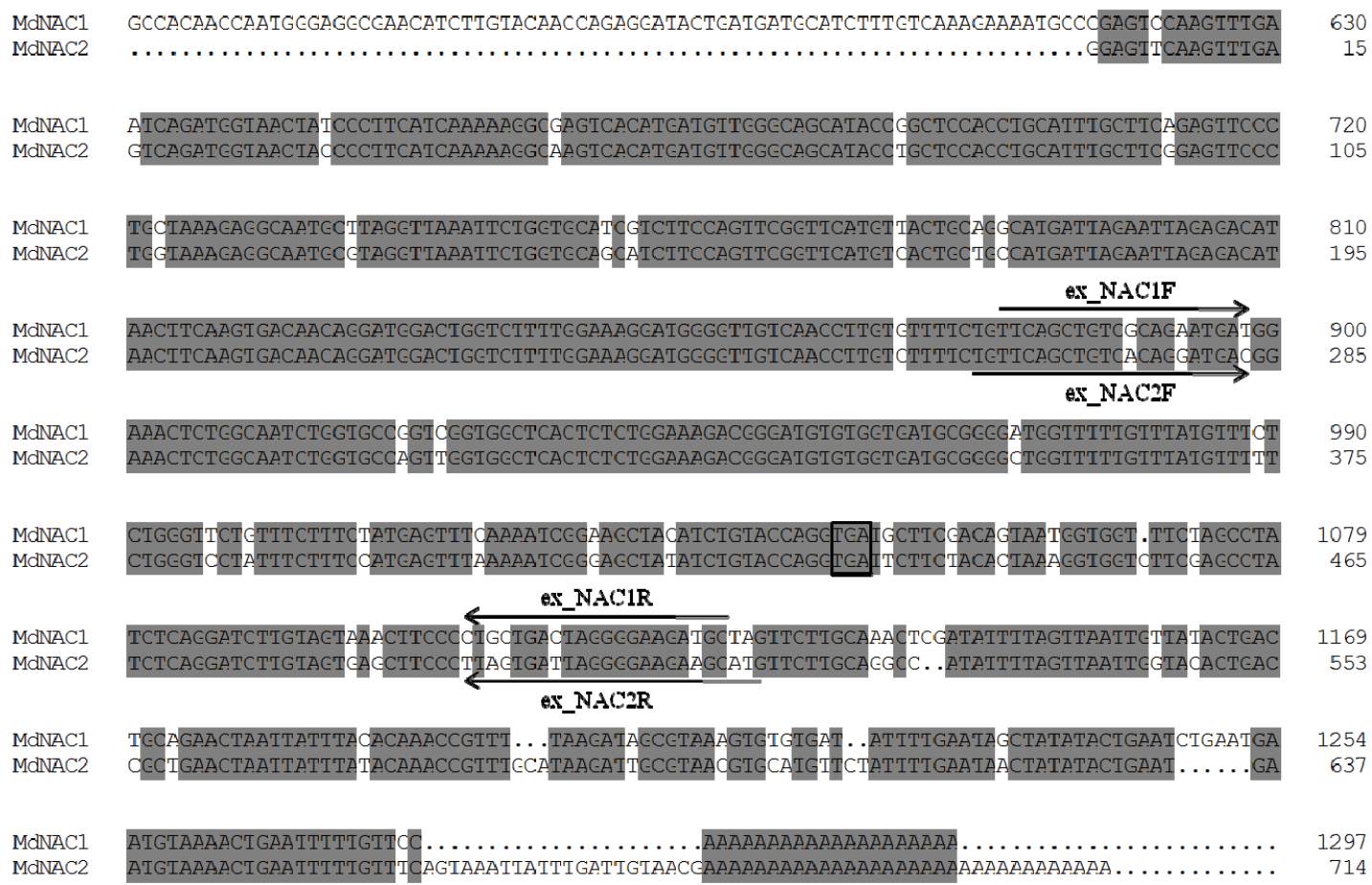

Figure 2. Comparison of the cDNA sequences at the 3'end of MdNAC1 (int9) and MdNAC2 (int10)

Identical nucleotides were shaded in gray. The stop codon was boxed. The primer sequences used for gene expression assays were indicated with arrows.

\subsection{Evaluation of Fruit Ethylene Production and Firmness}

For each sampling point of five fruit, fruit were weighed individually and enclosed in an air-tight container of 1.891 (Model 7K24, Rubbermaid, Atlanta, GA. USA) equipped with septa for $1 \mathrm{~h}$ at $24{ }^{\circ} \mathrm{C}$. For each fruit, one milliliter $(1 \mathrm{ml})$ of the gas was sampled through the headspace of the container using a BD (Franklin Lakes, NJ, USA) syringe (BD Cat. \#309602). Ethylene concentration was measured with a gas chromatograph HP 5890 series II (Hewlett-Packard, Palo Alto, CA, USA) equipped with a flame ionization detector.

Flesh firmness was measured with a penetrometer (FT 327, McCormick, Facchini, Alfonsine, Italy) fitted with an $11.1 \mathrm{~mm}$-diameter probe. Four skin discs (approximately $2.5 \mathrm{~cm}$ in diameter) were removed from opposite sides of each fruit. For each of the four cut surfaces, the probe was pressed into a depth of 8 to $9 \mathrm{~mm}$ in a single smooth motion.

\subsection{Real-time Quantitative Reverse Transcription Polymerase Chain Reaction (qRT-PCR)}

RNA was isolated using the ZR Plant RNA MiniPrep kit (ZYMO Research, Irvine, CA, USA) according to the manufacturer's instruction. Three independent reverse transcription reactions, which began with $1 \mu \mathrm{g}$ of total RNA, were performed for each of the RNA samples using the Superscript III RT (Invitrogen, Carlsbad, CA, USA) by following the manufacturer's manual. The resulting first stand cDNA was diluted by 10 times, and then used as templates for qRT-PCR assays with the four sets of gene specific primers (Table 2): Primers ex_RTE1aF and ex_RTE1aR are for MdRTE1a, ex_RTE1bF and ex_RTE1bR for MdRTE1b, ex_NAC1F and ex_NAC1R for $M d N A \bar{C} 1$, and ex_NAC2F and ex_NAC2R for MdNAC2 (Table 2). The primer bases discriminating MdRTE1a from $M d R T E 1 b$, and $M d N A C 1$ from $M d N A C 2$ were indicated (Figures 1B, 2).

qRT-PCR was performed with the Roche (Indianapolis, IN, USA) LightCycler 480 Real-Time PCR System. For each reaction, a final volume of $20 \mu \mathrm{l}$ was used, which contained $5 \mu \mathrm{l}$ of the cDNA dilutions, $0.5 \mu \mathrm{M}$ of the forward and reverse primer, and $1 \times$ SYBR green master mix (Roche Cat. \# 04707516001). The qRT-PCR program included an initial denaturation step of $10 \mathrm{~min}$ at $94^{\circ} \mathrm{C}, 45$ cycles of amplification using $10 \mathrm{~s}$ at $94^{\circ} \mathrm{C}$, $25 \mathrm{~s}$ at $55^{\circ} \mathrm{C}$, and $25 \mathrm{~s}$ at $72^{\circ} \mathrm{C}$, and a dissociation stage of $5 \mathrm{~s}$ at $95^{\circ} \mathrm{C}, 60 \mathrm{~s}$ at $60^{\circ} \mathrm{C}$, and $15 \mathrm{~s}$ at $97^{\circ} \mathrm{C}$. The apple actin gene (EB136338) was amplified by primers Actin F and Actin R (Table 1) and used as a reference to the target genes. Expression quantification and data analysis were performed by LightCycler 480 Software (Version 
1.5) using the comparative cycle threshold method (Pfaffl, 2001). Comparison of means and test of statistic significance were performed with the JMP9.0 software (SAS Institute, Cary, NC, USA).

\section{Results}

\subsection{Characterization of the Y2H Library of 'Golden Delicious'}

The $\mathrm{Y} 2 \mathrm{H}$ library was constructed with the size fractioned cDNA $(>0.3 \mathrm{~kb})$ from the maturing/ripening GD fruit. Titration of the library on SD/-Leu plates indicated a titer of $1.2 \times 10^{7} \mathrm{cfu} / \mathrm{ml}$. A PCR survey of the insert size of 156 randomly selected clones using primers $\mathrm{Y} 2 \mathrm{H} \_$amp $\mathrm{F}$ and $\mathrm{Y} 2 \mathrm{H} \_$amp R (Table 1) found a mean size of $829 \pm 313 \mathrm{bp}$, ranging from 300 through $1700 \mathrm{bp}$ (data not shown), meeting the size expectations for the $\mathrm{Y} 2 \mathrm{H}$ library. Sequencing analysis of the first 62 clones showed that $47(75.8 \%)$ had at least one significant hit in GenBank while $15(24.2 \%)$ had no significant similarities (with an expect threshold at $10^{-9}$ ). The top five abundant genes surveyed in the library encode $M$. domestica metallothionein (MT)-like proteins including AMT2 (8.1\%) and AMT1 (4.8\%), MdACO1 (4.8\%), auxin-repressed protein-like protein (4.8\%) and abscisic stress ripening like protein $(3.2 \%)$.

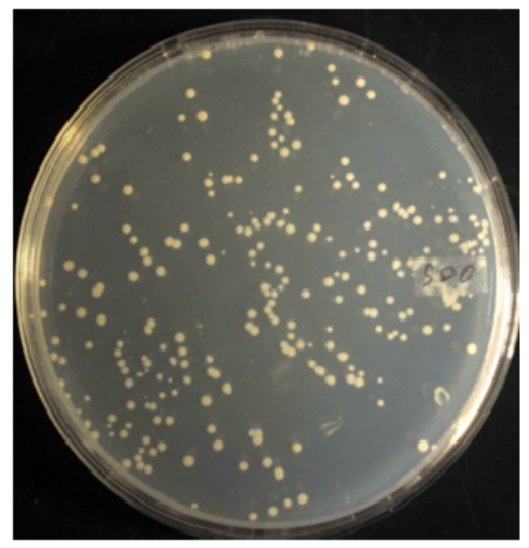

SDO

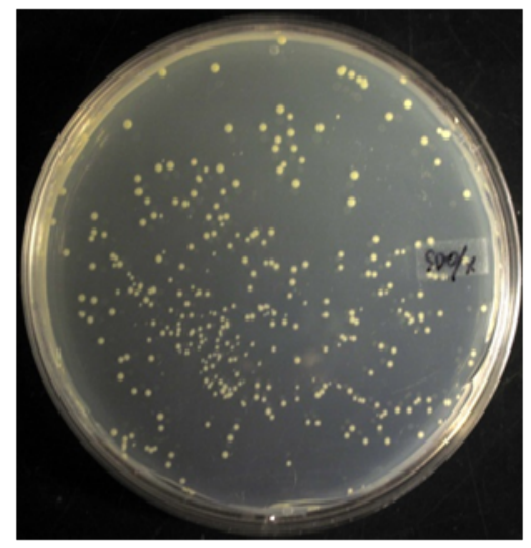

SDO/X

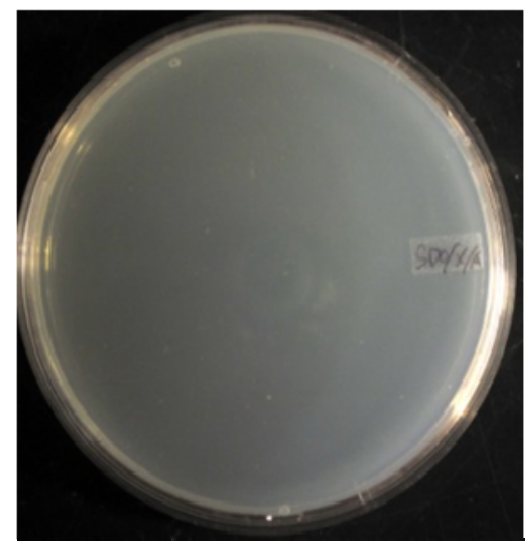

SDO/X/A

Figure 3. Auto-activation test of pGBKT7-RTE1a

Recombinant plasmid pGBKT7-RTE1a was transformed into yeast strain Y2HGold. Cells were spread on plates of single dropout medium (SD/-Trp, SDO), SDO plus X- $\alpha$-Gal medium (SDO/X), and SDO/X plus Aureobasidin A medium (SDO/X/A). Colonies were able to grow on the SDO and SDO/X plates, but not on the SDO/X/A plate. In addition, there were no blue colonies observed on the SDO/X plate. These growth characteristics indicate that pGBKT7-RTE1a does not have auto-activation activity and are suitable for Y2H library screening.

\subsection{Screening the Y2H Library for the Putative Interactors of MdRTE1a}

The entire coding region (predicted) of the MdRTE1a cDNA was inserted into the vector pGBKT7 to construct the bait construct pGBKT7-RTE1a. Before screening the Y2H library, the coding sequence of MdRTE1a was sequence confirmed to be in frame in the construct and the bait was proven to be free of auto-activation activity and toxicity when transformed into yeast cells (Figure 3). A total of 12 million cells (estimated) from the Y2H library were screened with the bait pGBKT7-RTE1a; the mating efficiency was estimated as $6.6 \%$. Despite being grown on the low stringency plates (DDO/X/A), there were only 35 positive colonies obtained from the screening. Sequencing analysis of the plasmids rescued from the 35 clones indicated that the 35 sequences could be aligned into three unique cDNA contigs. To further test the interactions, the hybrid colonies of the representative clones 'int9' (standing for 24 clones), 'int10' (for 8 clones) and 'int22' (for 3 clones) were streaked onto the high stringency plates $(\mathrm{QDO} / \mathrm{X} / \mathrm{A})$. The hybrid colonies of clones 'int9' and 'int10' survived well while that of clone 'int22' did not grow, suggesting clones 'int9' and 'int10' might genuinely interact with MdRTE1a. 


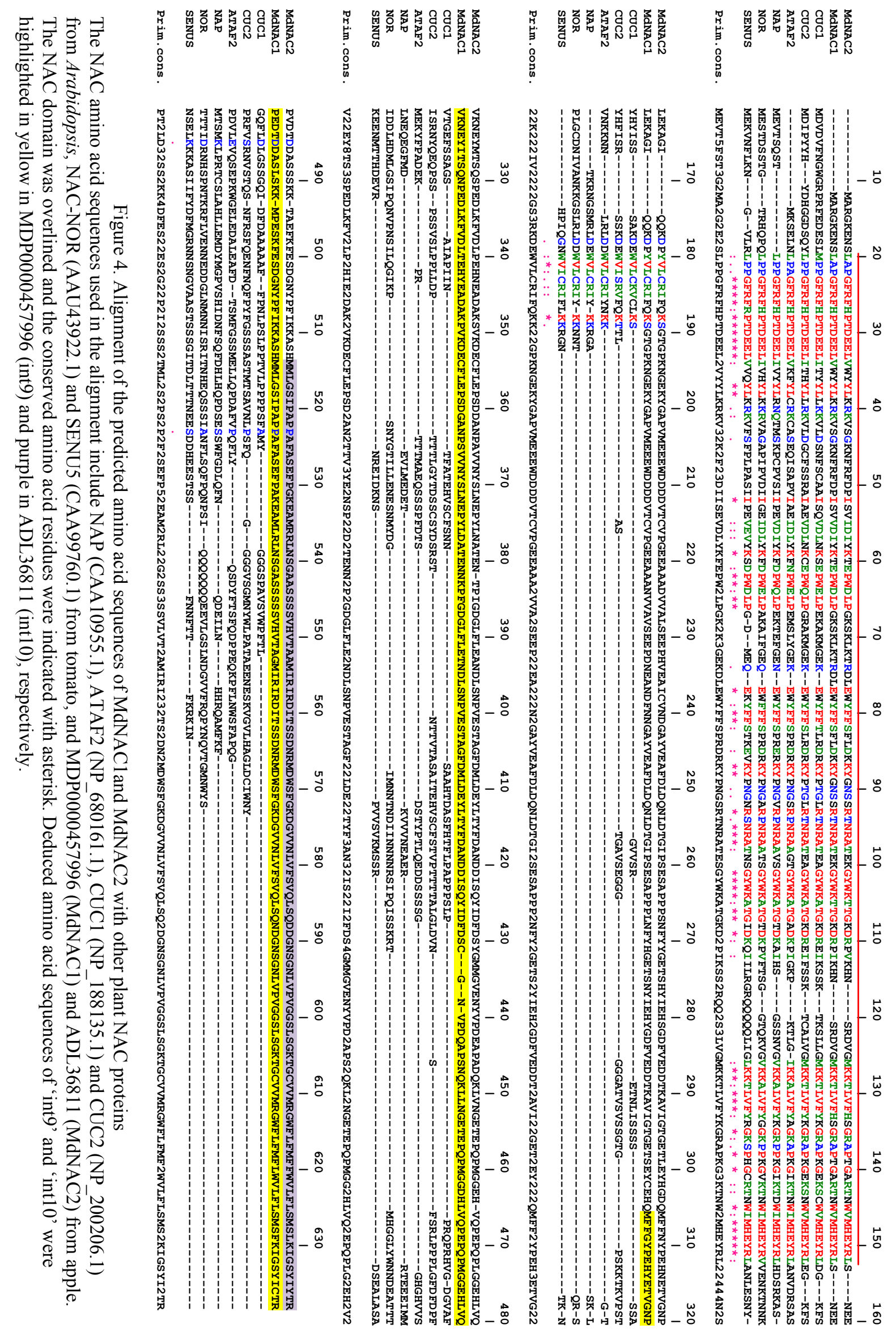


Blast searches against GenBank and the apple genome at GDR (Genome Database for Rosaceae) found that 'int9' is nearly identical to the C-terminus of both MDP0000457996 and MDP0000695714, the two duplicated genes/proteins closely located on chromosome 16 (thus likely to be allelic genes from the two haploid genomes), whereas 'int10' almost perfectly matches the C-terminus of protein ADL36811 in GenBank, or MDP0000621646 on chromosome 2. All these proteins contain a conserved NAC (NAM/ $\underline{A} T A F 1,2 / \underline{C U C}$ ) domain at their N-terminal region, characteristic of the NAC family of transcription factors (Figure 4). Thus clones 'int9' and 'int10', despite of their sequences do not contain the NAC domain (Figures 2, 4), represent at least two putative NAC transcription factors in apple, designated MdNAC1 (for MDP0000457996 and MDP0000695714) and MdNAC2 (for ADL36811 and MDP0000621646), respectively. MdNAC1 and MdNAC2 are highly related and share $93.2 \%$ of identity in their coding sequences. However, the 3'-UTR sequences of 'int9' and 'int 10' are identical only by $88.5 \%$ (Figure 2).

A

pGBKT7-RTE1a+pGADT7-NAC1

pGBKT7+pGADT7-NAC1

pGHKI /-KIH 1a+pGNIJI/-NAC)

pSBKT7+pGADT7-NAC2
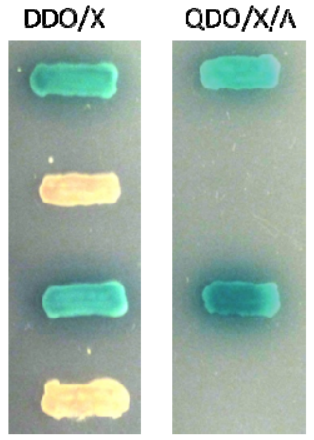

B

pGBKT7-RTE1b+pGADT7

pGBKT7 RTE1b+pGADT7 NAC1

pGBKT7 RTE1b+pGADT7 NAC2

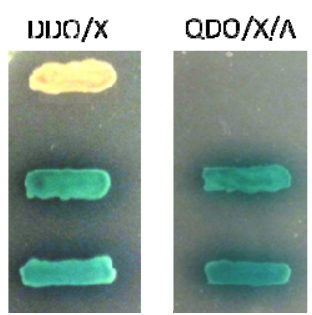

Figure 5. Confirmation of the interaction between MdRTE1 and MdNAC proteins in yeast cells

DDO/X: SD/-Trp/-Leu/X (X- $\alpha$-Gal). QDO/X/A： SD/-Trp/-Leu/-His/-Ade/X/A (Aureobasidin A). A: Co-transformation of pGBKT7-RTE1a and pGADT7-NAC1, pGBKT7-RTE1a and pGADT7-NAC2, pGBKT7 (empty vector) and pGADT7-NAC1 (CK), and pGBKT7 and pGADT7-NAC2 (CK). B: Co-transformation of pGBKT7-RTE1b and pGADT7-NAC1, pGBKT7-RTE1b and pGADT7-NAC2, and pGBKT7-RTE1b and pGADT7 (empty vector) (CK).

\subsection{Confirmation of Protein-protein Interactions in Yeast Cells}

To further confirm the interaction between MdRTE1a and the two NACs, pGADT7-NAC1 (coding region from int9) and -NAC2 (coding region from int10) were respectively co-transformed with pGBKT7-RTE1a into yeast strain Y2HGold. The transformant cells were grown on the DDO/X and QDO/X/A plates. The blue colonies on both plates (Figure 5A) indicated the positive interaction between pGBKT7-RTE1a and pGADT7-NAC1 or -NAC2. As controls, pGADT7-NAC1 or -NAC2 were also co-transformed with pGBKT7 empty vector into the yeast cells. But their colonies did not turn blue on $\mathrm{DDO} / \mathrm{X}$ plates and were not able to grow on $\mathrm{QDO} / \mathrm{X} / \mathrm{A}$ plates (Figure 5A), suggesting that pGADT7-NAC1 or -NAC2 alone is not able to activate the reporter genes. These results demonstrated that the interaction between MdRTE1a and MdNAC1 or MdNAC2 protein is positively confirmed in the yeast cells.

As described in the Materials and Methods section, MdRTE1a and MdRTE1b share 94.1\% identity in deduced amino acid sequences (Figure 1A). To investigate if MdRTE1b interacts with the two NACs, we constructed a recombinant plasmid of pGBKT7-RTE1b and co-transformed with pGADT7-NAC1 and -NAC2, respectively. 
The experiment showed that MdRTE1b also interacts with MdNAC1 and MdNAC2 in the yeast cells (Figure 5B), similar to MdRTE1a (Figure 5A).

A

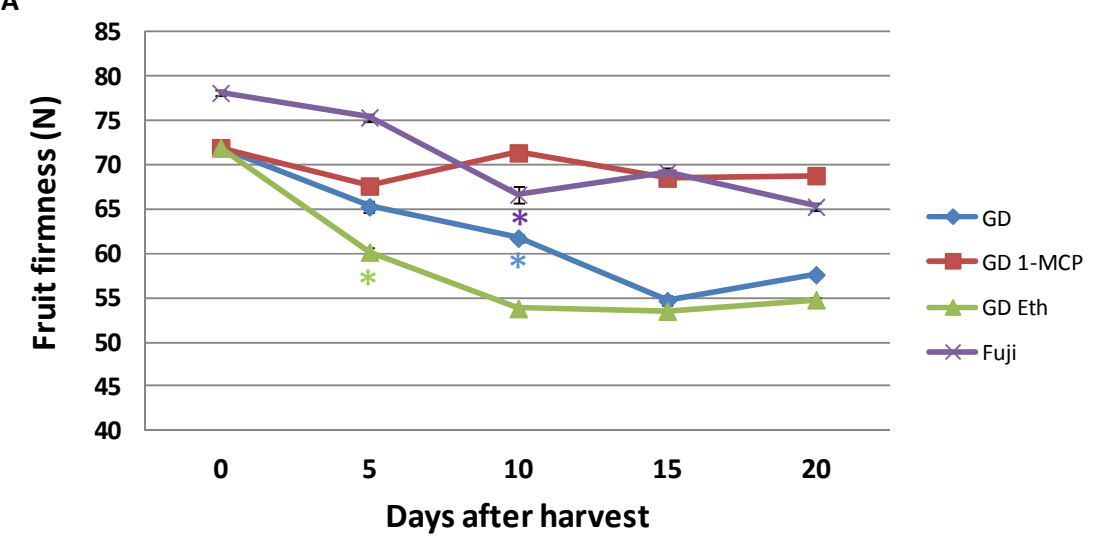

B

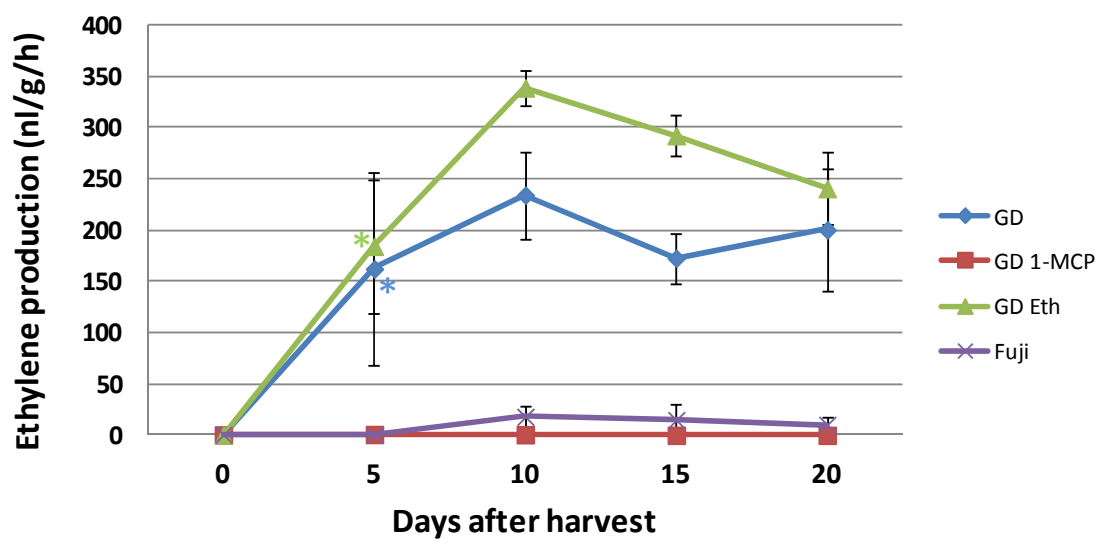

Figure 6. Changes in firmness and ethylene production of apple fruit during storage $\left(24^{\circ} \mathrm{C}\right)$

The bars represent SD measured in five fruit. *The first measurement showing significant change from $\mathrm{d} 0$ in fruit firmness or ethylene production $(\mathrm{P}<0.01)$. A: Fruit firmness of 'Golden Delicious' and 'Fuji': GD (untreated), GD 1-MCP (treated with 1-MCP), GD Eth (treated with ethephon) and 'Fuji' (untreated). B: Ethylene production.

\subsection{Fruit Firmness and Ethylene Production}

During postharvest storage of $20 \mathrm{~d}$ at room temperature (Figure 6A), the firmness of the untreated GD fruit decreased from $71.9 \mathrm{~N}$ to $57.6 \mathrm{~N}$, and this significant drop in firmness occurred in 10 days. The ethephon treated GD fruit lost more firmness (from $71.9 \mathrm{~N}$ to $54.7 \mathrm{~N}$ ) and quicker as the significant reduction of firmness was observed in five days. However, the GD fruit treated with 1-MCP did not soften significantly. The untreated 'Fuji' fruit showed a similar softening trend as the GD fruit, but had much higher flesh firmness during the test.

The ethylene production (Figure 6B) of the untreated GD fruit increased significantly in $5 \mathrm{~d}$ when stored at room temperature, and a burst of ethylene occurred at $10 \mathrm{~d}$. Ethephon treated GD fruit produced ethylene in a similar pattern to the untreated fruit, but at a higher level. 1-MCP treatment almost blocked ethylene production in GD fruit. Ethylene production in 'Fuji' was low and there was no significant increase during the storage.

\subsection{Expression Profile of MdRTE1a and MdRTE1b}

To understand the expression profile of MdRTE1a and MdRTE1b at various stages of fruit, GD fruit were sampled from 7 DAF (days after full-bloom) through harvest (140 DAF) and further through a storage of $20 \mathrm{~d}$ (Table 2, Figure 7). The expression of MdRTE1a was high at the early stages of fruit growth and development and then decreased through harvest although there was an increase at $35 \mathrm{DAF}$ and another increase at $133 \mathrm{DAF}$ (Figure 7A). During the storage, the expression of MdRTEla was largely consistently at low levels in the 
untreated GD fruit, and this pattern of low and consistent expression was not affected in the 1-MCP or ethephon treated GD fruit (Figure 7B). In addition, MdRTE1a expression in the untreated GD fruit did not show much difference from that in 'Fuji' although 'Fuji' had higher firmness and lower ethylene production than GD (Figure 6). To assess the expression of MdRTEla in different apple tissues, RNA from young leaves, flowers (at full bloom) and fruit (at harvest) of GD were used. MdRTE1a was expressed lowest in fruit, medium in flowers and highest in leaves (Figure 7C). These results suggested that MdRTE1a is likely a gene to function in growth rather than a gene that is related to fruit ripening and regulated by ethylene.

The expression of MdRTE1b was markedly different from that of MdRTE1a. It began with a level that was the highest (at 7 DAF) in the dataset (Figure 7D), and then followed by a sharp reduction (15-22 DAF). The lowest expression levels were observed from $28 \mathrm{DAF}$ through $133 \mathrm{DAF}$, the vastly major period for fruit growth and development. However, the expression of MdRTE1b was significantly increased at harvest (Figure 7D). During the storage, MdRTElb expression was elevated even higher in the untreated GD fruit (Figure 7E). In the ethephon treated GD fruit, MdRTE1b was similarly expressed as in the untreated controls, but with slightly lower levels at $\mathrm{d} 5$ and d 10, and slightly higher levels at d 15 and d 20 (Figure 7E). This suggested that there might be a negative feedback regulation in place, i.e. excessive ethylene may result in lower or insignificant promotion of $M d R T E 1 b$ expression. In the 1-MCP treated fruit, however, the expression of MdRTE1b was severely suppressed (Figure 7E). The expression of MdRTElb in 'Fuji' fruit was lower than that in GD fruit except for those at $\mathrm{d} 0$ and d 10 (Figure 7E). Among the three organs, fruit had higher expression of MdRTE1b than flowers and leaves did (Figure 7F). These data, therefore, indicated that MdRTE1b is most likely an apple ripening related gene and involved in ethylene signaling and response.

\subsection{Expression Profile of MdNAC1 and MdNAC2}

The expression pattern of $M d N A C 1$ was similar to that of MdRTE1a, i.e. high at the early stages of fruit growth and development and then declined through harvest (Figure 7G). During postharvest storage, MdNAC1 expression in the untreated GD fruit was low and was not affected by 1-MCP or ethephon treatment although there was a slight deviation from this trend at $\mathrm{d} 20$ (Figure 7H). Moreover, $M d N A C 1$ expression was similar in the fruit of both 'Fuji' and GD (untreated), and was higher in flowers and leaves than in fruit (Figure 7I). These results suggested that $M d N A C 1$ may play roles in apple growth, but unlikely in fruit ripening.

The expression of $M d N A C 2$ was similar to that of MdRTE1b, i.e. high at the initial stages of fruit growth and development and then become low and consistent through harvest (Figure 7J). In the untreated GD fruit, $M d N A C 2$ expression greatly increased at $\mathrm{d} 5$ and maintained at high levels throughout the storage (Figure 7K). $M d N A C 2$ expression was highly inhibited in the 1-MCP treated GD fruit; but the expression levels were also much lower in the ethephon treated fruit than in the control (Figure 7K). This indicated that $M d N A C 2$ expression is regulated by ethylene and excessive ethylene may also have a negative feedback regulation on the expression of $M d N A C 2$, similar to what has been suggested for MdRTE1b above. In addition, the expression of MdNAC2 was much higher in the untreated GD fruit than in 'Fuji' during the storage (Figure 7K), which was positively correlated with the fact that GD fruit produced much more ethylene than 'Fuji' fruit did during the same period of storage (Figure 6B). These results suggested that $M d N A C 2$ is likely a fruit ripening related gene and is involved in the ethylene signaling and response although its expression was higher in leaves and flowers than in fruit (Figure 7L).

\section{Discussion}

\subsection{Construction and Application of the Y2H Library of 'Golden Delicious'}

The $\mathrm{Y} 2 \mathrm{H}$ system is primarily used to screen a complete library of proteins for interactions with a specific protein of interest. Since its initial description (Ma \& Ptashne, 1988), the Y2H system has been used to detect and analyze protein-protein interactions in many studies (Bruckner, Polge, Lentze, Auerbach, \& Schlattner, 2009). In this report, we constructed a $\mathrm{Y} 2 \mathrm{H}$ library from the maturing/ripening fruit of GD. Based on the limited sequence survey of 62 clones, five genes are the most abundant in the library, including AMT2 (8.1\%), AMT1 (4.8\%), MdACO1 (4.8\%), auxin-repressed protein-like protein (4.8\%) and abscisic stress ripening like protein (3.2\%). The high abundance of these genes appears to be correlated with the developmental and ripening stages of the fruit used for constructing the library. In apple, AMT1 and $A M T 2$ have been reported to be highly expressed during the late fruit development and ripening stages especially for $A M T 2$ (Reid \& Ross, 1997). High expression of metallothionein genes during these stages has been observed in pear (Itai, Tanabe, Tamura, \& Tanaka, 2000) and pineapple (Moyle, Fairbairn, Ripi, Crowe, \& Botella, 2005). In addition, two tomato metallothionein (MT)-like protein coding genes, $\operatorname{LeMT}(A)$ and $\operatorname{LeMT}(B)$, are ethylene responsive (Whitelaw, LeHuquet, Thurman, \& Tomsett, 1997). It is known that $M d A C O 1$ is largely responsible for the burst of ethylene production 
in ripening fruit, consistent with its high abundance in the library. Screening the Y2H library enabled us to identify proteins, MdNAC1 and MdNAC2 interacting with MdRTE1a and MdRTE1b in the yeast cells, suggesting that the $\mathrm{Y} 2 \mathrm{H}$ library does have applications for screening protein-protein interactions involved in ethylene signaling and response in maturing/ripening apple fruit.

\section{MdRTE1a}

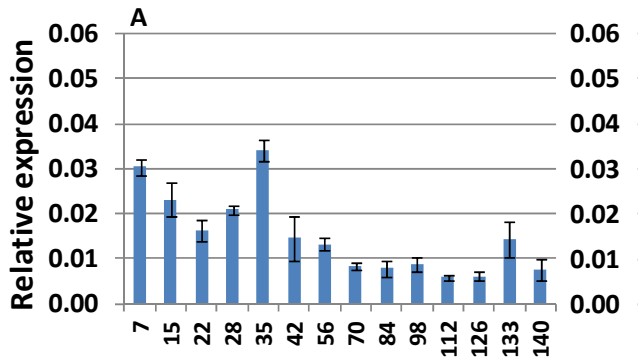

\section{MdRTE1b}

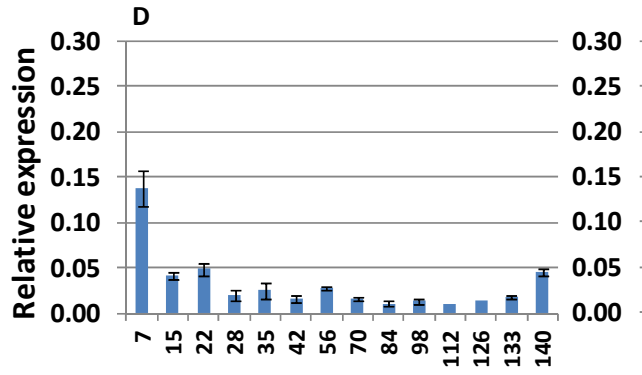

\section{MdNAC1}

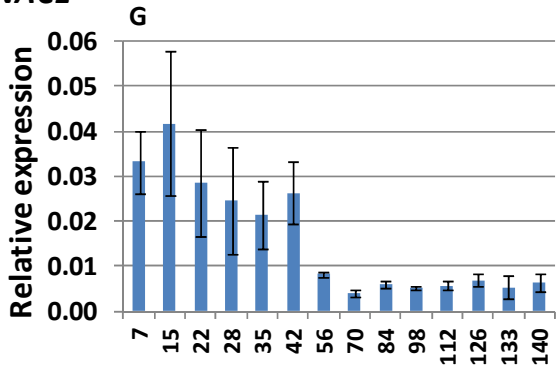

MdNAC2

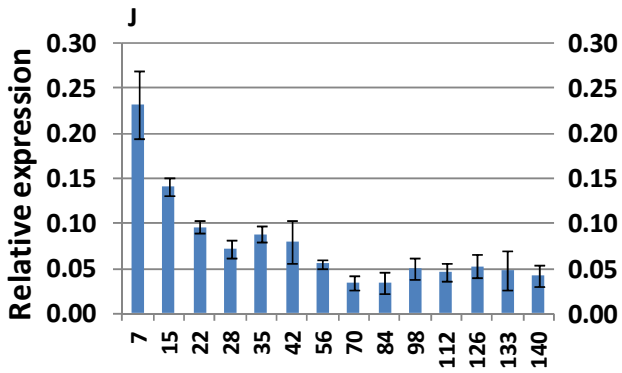

Days after full-bloom

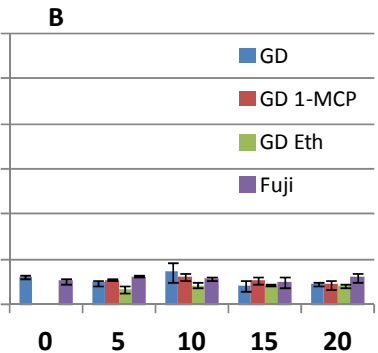

E
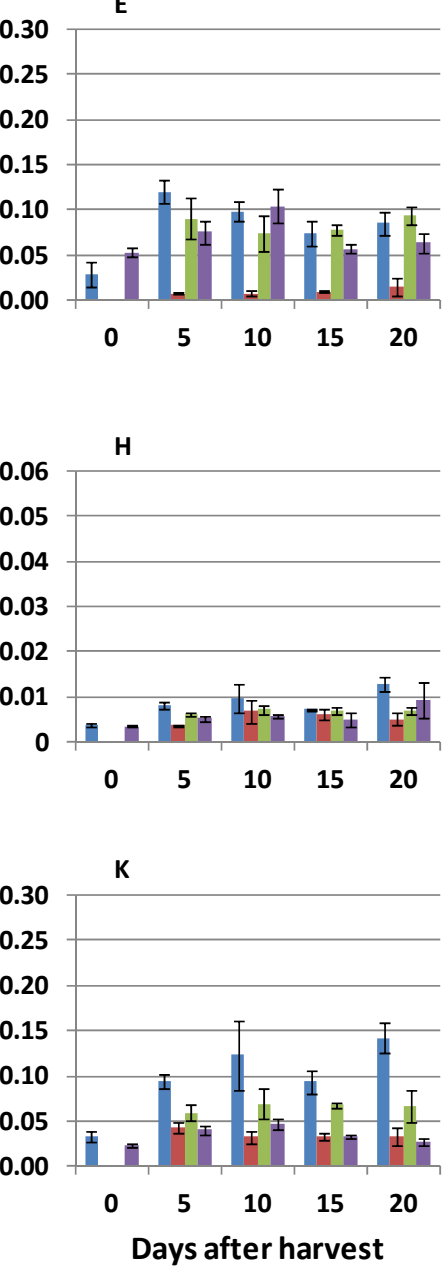
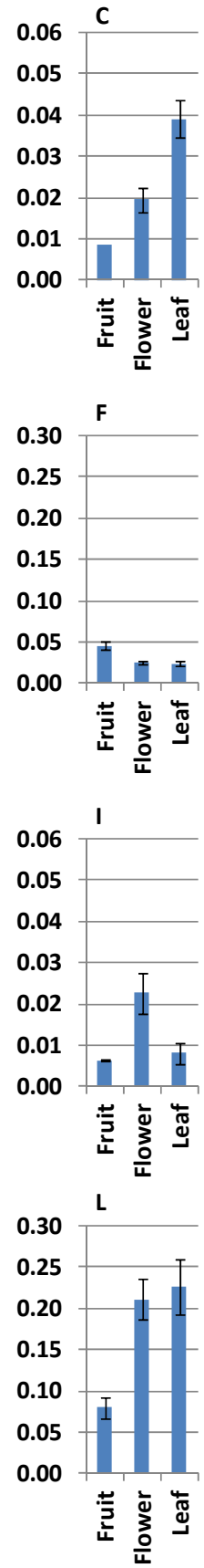

Figure 7. qRT-PCR assays of MdRTE1a, MdRTE1b, MdNAC1 and MdNAC2

Expression of each gene is presented as relative fold change over the reference gene (actin). The bars represent SD measured from three replicates. A, D, G and J: Assays on the GD's fruit under growth and development (pre-harvest). B, E, H and K: Assays on the postharvest fruit of GD and 'Fuji'. GD (untreated), GD 1-MCP (treated with 1-MCP), GD Eth (treated with ethephon) and 'Fuji' (untreated). C, F, I and L: Assays on the fruit (at harvest), flowers (at full bloom) and young leaves of GD. 


\subsection{Expression of MdRTE1a, MdRTE1b, MdNAC1 and MdNAC2}

RTE1 is a novel protein conserved in plants (Barry \& Giovannoni, 2006; Resnick et al., 2006). The expression of RTE1 was inducible by ethylene and over-expression of RTE1 reduced ethylene sensitivity in Arabidopsis (Resnick et al., 2006). In tomato, over-expression of $G R$, a $R T E 1$ ortholog, blocked fruit from ripening (Barry \& Giovannoni, 2006). These results indicated that RTE1 and GR function in ethylene signaling and/or fruit ripening. In this study, the expression of MdRTE1b was quickly enhanced in the untreated GD fruit during ripening (Figure 7E) and was highly inhibited by 1-MCP, indicating that MdRTE1b expression is under the regulation of ethylene and involved in apple fruit ripening. Thus, it is likely that MdRTE1b is the apple counterpart of RTE1 in Arabidopsis. However, the means by which MdRTE1b functions appeared to be in contrast with that of RTE1 and GR as higher expression of MdRTE1b is associated with higher ethylene production and greater fruit firmness loss in GD (i.e. increased ethylene sensitivity and accelerated ripening process) while lower expression of MdRTE1b is correlated with lower ethylene production and less fruit firmness loss (i.e. decreased ethylene sensitivity and prohibited ripening process) in 'Fuji' (Figure 7E).

In Arabidopsis, there is a related gene of RTE1, called RTH (RTE1 HOMOLOG) (Barry \& Giovannoni, 2007; Resnick et al., 2006). RTE1 was reported to associate with one of the ethylene receptors, ETR1, while RTH does not have the same role as RTE1 in ethylene signaling (Dong et al., 2010). Based on our results, the expression of MdRTE1 $a$ is low and consistant in the untreated GD and 'Fuji' fruit during storage, and is not affected by 1-MCP or ethephon treatment (Figure 7B). These results suggested that MdRTE1a may not be involved in fruit ripening and ethylene regulation, similar to $R T H$ in Arabidopsis (Dong et al., 2010). This similarity may partially explain why an apple ETR1 was not identified from the Y2H library when screened with MdRTE1a as bait in this study. MdRTEla is expressed more in apple leaves and young fruit than in ripening fruit (Figure 7A-C), indicating that it may play roles in growth, but not in fruit ripening.

NAC proteins, characterized by a conserved NAC domain in N-terminus, are a large family of plant-specific transcription factors (Aida, Ishida, Fukaki, Fujisawa, \& Tasaka, 1997; Mita, Henmi, \& Ohno, 2006; Olsen, Ernst, Lo Leggio, \& Skriver, 2005). There are 117 NAC genes in Arabidopsis, 151 in rice (Nuruzzaman et al., 2010) and 163 in Populus (Hu et al., 2010). NAC transcription factors regulate diverse biological processes, including stress response, growth and development, and signaling of major plant hormones such as auxin, ABA, jasminate and ethylene (Fan, Gao, Yang, Deng, \& Li, 2007; He et al., 2005; Jiang, Li, Bu, \& Li, 2009; Olsen et al., 2005). In Arabidopsis, AtNAC2 is induced by ethylene precursor ACC treatment (He et al., 2005). A Cymbidium NAC gene is expressed abundantly when ethylene production burst occurred during necrosis of young inflorescences (Mita et al., 2006). All these results led to a conclusion that NAC genes are also involved in ethylene signaling and response. In this study, the expression of MdNAC2 increased in the untreated GD fruit during ripening (Figure 7K), and was highly inhibited in the 1-MCP treated GD fruit, indicating that a modulation of ethylene on its action likely exists. More interestingly, the expression of $M d N A C 2$ in the ethephon treated GD fruit was even lower than that in the untreated GD fruit, suggesting that excessive ethylene might have a negative feedback regulation on the expression of $M d N A C 2$. Such negative feedback regulation of excessive ethylene was also similarly observed for the expression of MdRTE1b (Figure 7E).

NOR (AY573802), another NAC gene in tomato, was isolated based on a tomato mutant non-ripening (nor), fruit of which neither produce climacteric ethylene nor ripen (Giovannoni, 2004). NOR regulates tomato fruit ripening, but it is not clear if it directly modulates ripening or via ethylene (Giovannoni, 2004; Lin, Zhong, \& Grierson, 2009). According to the evidence in this study, MdNAC2 may regulate fruit ripening through ethylene signaling by interacting with MdRTE1b. Furthermore, the expression of $M d N A C 2$ was much higher in untreated GD fruit than in 'Fuji' fruit (Figure 7K), which showed much longer shelf life (less softening and lower ethylene production) than GD fruit. These results indicated that low expression of $M d N A C 2$ in 'Fuji' could serve an important part in explaining its high keeping quality.

In addition, the expression of $M d N A C 1$ and $M d N A C 2$ was strong in apple flowers (Figure 7I, L), suggesting their function in embryonic and floral development as addressed in Olsen et al. (2005). The high expression of $M d N A C 2$ in apple leaves (Figure 7L) is indicative of its role in vegetative growth (Mallory, Dugas, Bartel, \& Bartel, 2004; Olsen et al., 2005). Both $M d N A C 1$ and $M d N A C 2$ were strongly expressed in early stage of fruit growth and development (Figure 7G, J), suggesting that the NAC proteins might be involved in fruit cell differentiation.

\subsection{The Interactions between MdRTE1s and MdNACs}

MdRTE1a and MdRTE1b were found to interact with MdNAC1 and MdNAC2 in yeast cells. Because of the similar expression patterns between MdRTE1a and MdNAC1, and between MdRTE1b and MdNAC2, it is 
possible that MdRTE1a and MdNAC1 might interact in actively growing organs and play roles in growth while MdRTE1b and MdNAC2 primarily in maturing/ripening fruit and function in ethylene signaling and/or fruit ripening.

The sequences of the $M d N A C 1$ and $M d N A C 2$ clones in the $\mathrm{Y} 2 \mathrm{H}$ library only contain the $\mathrm{C}$-terminal region (Figure 4); and neither has the N-terminal sequences in which the conserved NAC domain is located. In other words, the interactions between the MdRTE1s and MdNACs took place in the C-terminus of the two NAC proteins in yeast cells. However, we cannot exclude the possibility that the real world interactions between the MdRTE1s and MdNACs in apple cells, if they exist, could also involve the N-terminus of MdNACs although the NAC domain has been considered to have DNA-binding ability (Olsen et al., 2005).

The C-terminus of NAC proteins has been reported capable of activating gene expression (Duval, Hsieh, Kim, \& Thomas, 2002; Meng, Cai, Zhang, \& Guo, 2009; Ooka et al., 2003; Robertson, 2004). Duval et al. (2002) found that a C-terminal deletion construct of AtNAM was not able to activate a reporter gene in a yeast one-hybrid assay. It is possible that MdNAC1 and MdNAC2 may activate the transcription of MdRTE1s by their C-terminal interactions. Thus, MdNAC2 might be positioned at the top of MdRTE1b in ethylene signal transduction pathway. MdNAC2 might also function downstream of MdRTE1b through an unknown pathway or by bridging MdRTE1b and other components in the pathway. Further studies are needed to ensure the interaction between MdRTE1b and MdNAC2 and their functions in apple fruit ripening and ethylene signaling. It would be interesting to investigate whether MdRTE1b interacts with MdNAC2 in apple fruit or other plant cells using the bimolecular fluorescence complementation (BiFC) system. Detailed functional characterization of MdRTE1b and MdNAC2 would increase our understanding of apple fruit ripening.

In conclusion, apple MdRTE1a and MdRTE1b putatively interact with both MdNAC1 and MdNAC2 proteins in yeast cells. MdRTE1b is probably the apple counterpart of RTE1 in Arabidopsis. MdRTE1b and MdNAC2 may play an important role in fruit ripening and ethylene signaling, whereas MdRTE1a and MdNAC1 primarily function in the growth of young fruit, flowers and leaves.

\section{Acknowledgements}

We sincerely thank Drs Susan Brown and Christopher Watkins for their critical review of this manuscript. We also thank Dr. Brown for providing the apple trees for fruit sampling, Dr. Watkins for helping with 1-MCP treatment of the fruit, and Xia Xu, Yang Bai and Tuanhui Bai for technical assistance.

\section{References}

Adams, D. O., \& Yang, S. F. (1979). Ethylene Biosynthesis - Identification of 1-Aminocyclopropane-1-Carboxylic Acid as an Intermediate in the Conversion of Methionine to Ethylene. Proceedings of the National Academy of Sciences of the United States of America, 76(1), 170-174. http://dx.doi.org/10.1073/pnas.76.1.170

Adams-Phillips, L., Barry, C., Kannan, P., Leclercq, J., Bouzayen, M., \& Giovannoni, J. (2004). Evidence that CTR1-mediated ethylene signal transduction in tomato is encoded by a multigene family whose members display distinct regulatory features. Plant Molecular Biology, 54(3), 387-404. http://dx.doi.org/10.1023/B:PLAN.0000036371.30528.26

Aida, M., Ishida, T., Fukaki, H., Fujisawa, H., \& Tasaka, M. (1997). Genes involved in organ separation in Arabidopsis: An analysis of the cup-shaped cotyledon mutant. Plant Cell, 9(6), 841-857. http://dx.doi.org/10.1105/tpc.9.6.841

Barry, C. S., \& Giovannoni, J. J. (2006). Ripening in the tomato Green-ripe mutant is inhibited by ectopic expression of a protein that disrupts ethylene signaling. Proceedings of the National Academy of Sciences of the United States of America, 103(20), 7923-7928. http://dx.doi.org/10.1073/pnas.0602319103

Barry, C. S., \& Giovannoni, J. J. (2007). Ethylene and fruit ripening. Journal of Plant Growth Regulation, 26(2), 143-159. http://dx.doi.org/10.1007/s00344-007-9002-y

Barry, C. S., McQuinn, R. P., Thompson, A. J., Seymour, G. B., Grierson, D., \& Giovannoni, J. J. (2005). Ethylene insensitivity conferred by the Green-ripe and Never-ripe 2 ripening mutants of tomato. Plant Physiology, 138(1), 267-275. http://dx.doi.org/10.1104/pp.104.057745

Bruckner, A., Polge, C., Lentze, N., Auerbach, D., \& Schlattner, U. (2009). Yeast Two-Hybrid, a Powerful Tool for Systems Biology. International Journal of Molecular Sciences, 10(6), 2763-2788. http://dx.doi.org/10.3390/ijms10062763 
Dal Cin, V., Danesin, M., Boschetti, A., Dorigoni, A., \& Ramina, A. (2005). Ethylene biosynthesis and perception in apple fruitlet abscission (Malus domestica L. Borck). Journal of Experimental Botany, 56(421), 2995-3005. http://dx.doi.org/10.1093/jxb/eri296

Dal Cin, V., Danesin, M., Botton, A., Boschetti, A., Dorigoni, A., \& Ramina, A. (2007). Fruit load and elevation affect ethylene biosynthesis and action in apple fruit (Malus domestica L. Borkh) during development, maturation and ripening. Plant Cell and Environment, 30(11), 1480-1485. http://dx.doi.org/10.1111/j.1365-3040.2007.01723.x

Dal Cin, V., Rizzini, F. M., Botton, A., \& Tonutti, P. (2006). The ethylene biosynthetic and signal transduction pathways are differently affected by 1-MCP in apple and peach fruit. Postharvest Biology and Technology, 42(2), 125-133. http://dx.doi.org/10.1016/j.postharvbio.2006.06.008

Dong, C. H., Jang, M., Scharein, B., Malach, A., Rivarola, M., Liesch, J., ... Chang, C. (2010). Molecular association of the Arabidopsis ETR1 ethylene receptor and a regulator of ethylene signaling, RTE1. Journal Biological Chemistry, 285(52), 40706-40713. http://dx.doi.org/10.1074/jbc.M110.146605

Duval, M., Hsieh, T. F., Kim, S. Y., \& Thomas, T. L. (2002). Molecular characterization of AtNAM: a member of the Arabidopsis NAC domain superfamily. Plant Molecular Biology, 50(2), 237-248. http://dx.doi.org/10.1023/A:1016028530943

Fan, J., Gao, X., Yang, Y. W., Deng, W., \& Li, Z. G. (2007). Molecular cloning and characterization of a NAC-like gene in "navel" orange fruit response to postharvest stresses. Plant Molecular Biology Reporter, 25(3-4), 145-153. http://dx.doi.org/10.1007/s11105-007-0016-1

Giovannoni, J. J. (2004). Genetic regulation of fruit development and ripening. Plant Cell, 16, S170-S180. http://dx.doi.org/10.1105/tpc.019158

He, X. J., Mu, R. L., Cao, W. H., Zhang, Z. G., Zhang, J. S., \& Chen, S. Y. (2005). AtNAC2, a transcription factor downstream of ethylene and auxin signaling pathways, is involved in salt stress response and lateral root development. Plant Journal, 44(6), 903-916. http://dx.doi.org/10.1111/j.1365-313X.2005.02575.x

Hu, R. B., Qi, G. A., Kong, Y. Z., Kong, D. J., Gao, Q. A., \& Zhou, G. K. (2010). Comprehensive Analysis of NAC Domain Transcription Factor Gene Family in Populus trichocarpa. Bmc Plant Biology, 10, 145. http://dx.doi.org/10.1186/1471-2229-10-145

Itai, A., Tanabe, K., Tamura, F., \& Tanaka, T. (2000). Isolation of cDNA clones corresponding to genes expressed during fruit ripening in Japanese pear (Pyrus pyrifolia Nakai): involvement of the ethylene signal transduction pathway in their expression. Journal of Experimental Botany, 51(347), 1163-1166. http://dx.doi.org/10.1093/jexbot/51.347.1163

Jiang, H., Li, H., Bu, Q., \& Li, C. (2009). The RHA2a-interacting proteins ANAC019 and ANAC055 may play a dual role in regulating ABA response and jasmonate response. Plant Signaling \& Behavior, 4(5), 464-466. http://dx.doi.org/10.4161/psb.4.5.8543

Kendrick, M. D., \& Chang, C. (2008). Ethylene signaling: new levels of complexity and regulation. Current Opinion in Plant Biology, 11(5), 479-485. http://dx.doi.org/10.1016/j.pbi.2008.06.011

Kondo, S., Meemak, S., Ban, Y., Moriguchi, T., \& Harada, T. (2009). Effects of auxin and jasmonates on 1-aminocyclopropane-1-carboxylate (ACC) synthase and ACC oxidase gene expression during ripening of apple fruit. Postharvest Biology and Technology, 51(2), 281-284. http://dx.doi.org/10.1016/j.postharvbio.2008.07.012

Lay-Yee, M., Dellapenna, D., \& Ross, G. S. (1990). Changes in messenger RNA and protein during ripening in apple fruit (Malus domestica Borkh. cv Golden Delicious). Plant Physiology, 94(2), 850-853. http://dx.doi.org/10.1104/pp.94.2.850

Li, J. G., \& Yuan, R. C. (2008). NAA and ethylene regulate expression of genes related to ethylene biosynthesis, perception, and cell wall degradation during fruit abscission and ripening in 'Delicious' apples. Journal of Plant Growth Regulation, 27(3), 283-295. http://dx.doi.org/10.1007/s00344-008-9055-6

Lin, Z. F., Alexander, L., Hackett, R., \& Grierson, D. (2008). LeCTR2, a CTR1-like protein kinase from tomato, plays a role in ethylene signalling, development and defence. Plant Journal, 54(6), 1083-1093. http://dx.doi.org/10.1111/j.1365-313X.2008.03481.x

Lin, Z. F., Zhong, S. L., \& Grierson, D. (2009). Recent advances in ethylene research. Journal of Experimental Botany, 60(12), 3311-3336. http://dx.doi.org/10.1093/jxb/erp204 
Ma, J., \& Ptashne, M. (1988). Converting a eukaryotic transcriptional inhibitor into an activator. Cell, 55(3), 443-446. http://dx.doi.org/10.1016/0092-8674(88)90030-X

Mallory, A. C., Dugas, D. V., Bartel, D. P., \& Bartel, B. (2004). MicroRNA regulation of NAC-domain targets is required for proper formation and separation of adjacent embryonic, vegetative, and floral organs. Current Biology, 14(12), 1035-1046. http://dx.doi.org/10.1016/j.cub.2004.06.022

Meng, C. M., Cai, C. P., Zhang, T. Z., \& Guo, W. Z. (2009). Characterization of six novel NAC genes and their responses to abiotic stresses in Gossypium hirsutum L. Plant Science, 176(3), 352-359. http://dx.doi.org/10.1016/j.plantsci.2008.12.003

Mita, S., Henmi, R., \& Ohno, H. (2006). Enhanced expression of genes for ACC synthase, ACC oxidase, and NAC protein during high-temperature-induced necrosis of young inflorescences of Cymbidium. Physiologia Plantarum, 128(3), 476-486. http://dx.doi.org/10.1111/j.1399-3054.2006.00759.x

Moyle, R., Fairbairn, D. J., Ripi, J., Crowe, M., \& Botella, J. R. (2005). Developing pineapple fruit has a small transcriptome dominated by metallothionein. Journal of Experimental Botany, 56(409), 101-112. http://dx.doi.org/10.1093/jxb/eri015

Nuruzzaman, M., Manimekalai, R., Sharoni, A. M., Satoh, K., Kondoh, H., Ooka, H., \& Kikuchia, S. (2010). Genome-wide analysis of NAC transcription factor family in rice. Gene, 465(1-2), 30-44. http://dx.doi.org/10.1016/j.gene.2010.06.008

Olsen, A. N., Ernst, H. A., Lo Leggio, L., \& Skriver, K. (2005). NAC transcription factors: structurally distinct, functionally diverse. Trends in Plant Science, 10(2), 79-87. http://dx.doi.org/10.1016/j.tplants.2004.12.010

Ooka, H., Satoh, K., Doi, K., Nagata, T., Otomo, Y., Murakami, K., ... Kikuchi, S. (2003). Comprehensive analysis of NAC family genes in Oryza sativa and Arabidopsis thaliana. DNA Research, 10(6), 239-247. http://dx.doi.org/10.1093/dnares/10.6.239

Pfaffl, M. W. (2001). A new mathematical model for relative quantification in real-time RT-PCR. Nucleic Acids Research, 29(9), e45. http://dx.doi.org/10.1093/nar/29.9.e45

Reid, S. J., \& Ross, G. S. (1997). Up-regulation of two cDNA clones encoding metallothionein-like proteins in apple fruit during cool storage. Physiologia Plantarum, 100(1), 183-189. http://dx.doi.org/10.1111/j.1399-3054.1997.tb03471.x

Resnick, J. S., Rivarola, M., \& Chang, C. (2008). Involvement of RTE1 in conformational changes promoting ETR1 ethylene receptor signaling in Arabidopsis. Plant Journal, 56(3), 423-431. http://dx.doi.org/10.1111/j.1365-313X.2008.03615.x

Resnick, J. S., Wen, C. K., Shockey, J. A., \& Chang, C. (2006). REVERSION-TO-ETHYLENE SENSITIVITY1, a conserved gene that regulates ethylene receptor function in Arabidopsis. Proceedings of the National Academy of Sciences of the United States of America, 103(20), 7917-7922. http://dx.doi.org/10.1073/pnas.0602239103

Rivarola, M., McClellan, C. A., Resnick, J. S., \& Chang, C. (2009). ETR1-Specific Mutations Distinguish ETR1 from Other Arabidopsis Ethylene Receptors as Revealed by Genetic Interaction with RTE1. Plant Physiology, 150(2), 547-551. http://dx.doi.org/10.1104/pp.109.138461

Robertson, M. (2004). Two transcription factors are negative regulators of gibberellin response in the HvSPY-signaling pathway in barley aleurone. Plant Physiology, 136(1), 2747-2761. http://dx.doi.org/10.1104/pp.104.041665

Stepanova, A. N., \& Alonso, J. M. (2009). Ethylene signaling and response: where different regulatory modules meet. Current Opinion in Plant Biology, 12(5), 548-555. http://dx.doi.org/10.1016/j.pbi.2009.07.009

Tacken, E., Ireland, H., Gunaseelan, K., Karunairetnam, S., Wang, D., Schultz, K., ...Schaffer, R. J.. (2010). The Role of Ethylene and Cold Temperature in the Regulation of the Apple POLYGALACTURONASE1 Gene and Fruit Softening. Plant Physiology, 153(1), 294-305. http://dx.doi.org/10.1104/pp.109.151092

Tatsuki, M., \& Endo, A. (2006). Analyses of expression patterns of ethylene receptor genes in apple (Malus domestica Borkh.) fruit treated with or without 1-methylcyclopropene (1-MCP). Journal of the Japanese Society for Horticultural Science, 75(6), 481-487. http://dx.doi.org/10.2503/jjshs.75.481

Tatsuki, M., Endo, A., \& Ohkawa, H. (2007). Influence of time from harvest to 1-MCP treatment on apple fruit quality and expression of genes for ethylene biosynthesis enzymes and ethylene receptors. Postharvest Biology and Technology, 43(1), 28-35. http://dx.doi.org/10.1016/j.postharvbio.2006.08.010 
Tatsuki, M., Hayama, H., \& Nakamura, Y. (2009). Apple ethylene receptor protein concentrations are affected by ethylene, and differ in cultivars that have different storage life. Planta, 230(2), 407-417. http://dx.doi.org/10.1007/s00425-009-0953-z

Velasco, R., Zharkikh, A., Affourtit, J., Dhingra, A., Cestaro, A., Kalyanaraman, A., ... Malnoy, M. (2010). The genome of the domesticated apple (Malus $\mathrm{x}$ domestica Borkh.). Nat Genet, 42, 833-839. http://dx.doi.org/10.1038/ng.654

Wang, A. D., Tan, D. M., Tatsuki, M., Kasai, A., Li, T. Z., Saito, H., ... Haradaa, T. (2009). Molecular mechanism of distinct ripening profiles in 'Fuji' apple fruit and its early maturing sports. Postharvest Biology and Technology, 52(1), 38-43. http://dx.doi.org/10.1016/j.postharvbio.2008.09.001

Wang, A., Tan, D., Takahashi, A., Li, T. Z., \& Harada, T. (2007). MdERFs, two ethylene-response factors involved in apple fruit ripening. Journal of Experimental Botany, 58(13), 3743-3748. http://dx.doi.org/10.1093/jxb/erm224

Whitelaw, C. A., LeHuquet, J. A., Thurman, D. A., \& Tomsett, A. B. (1997). The isolation and characterisation of type II metallothionein-like genes from tomato (Lycopersicon esculentum L). Plant Molecular Biology, 33(3), 503-511. http://dx.doi.org/10.1023/A:1005769121822

Wiersma, P. A., Zhang, H., Lu, C., Quail, A., \& Toivonen, P. M. A. (2007). Survey of the expression of genes for ethylene synthesis and perception during maturation and ripening of 'Sunrise' and 'Golden Delicious' apple fruit. Postharvest Biology and Technology, 44(3), 204-211. http://dx.doi.org/10.1016/j.postharvbio.2006.12.016

Yang, S. F., \& Hoffman, N. E. (1984). Ethylene Biosynthesis and Its Regulation in Higher-Plants. Annual Review of Plant Physiology and Plant Molecular Biology, 35, 155-189. http://dx.doi.org/10.1146/annurev.arplant.35.1.155

Zegzouti, H., Jones, B., Frasse, P., Marty, C., Maitre, B., Latche, A., ... Bouzayen, M. (1999). Ethylene-regulated gene expression in tomato fruit: characterization of novel ethylene-responsive and ripening-related genes isolated by differential display. Plant Journal, 18(6), 589-600. http://dx.doi.org/10.1046/j.1365-313x.1999.00483.x

Zhou, X., Liu, Q., Xie, F., \& Wen, C. K. (2007). RTE1 is a golgi-associated and ETR1-dependent negative regulator of ethylene responses. Plant Physiology, 145(1), 75-86. http://dx.doi.org/10.1104/pp.107.104299 